\title{
Long-term behavior of connections for glubam-concrete composite
}

\section{beams}

Xin $\mathrm{Ye}^{1}$, Bo Shan ${ }^{1,2}$, Qian $\mathrm{Yue}^{3}$ and Zhenyu Wang ${ }^{4}$

${ }^{1}$ College of Civil Engineering, Hunan University, 410082 Changsha, China

${ }^{2}$ Key Laboratory for Green \& Advanced Civil Engineering Materials and Application Technology of Hunan Province, Changsha 410082, China

${ }^{3}$ Capio International \& Associate Group, 410082 Changsha, China

${ }^{4}$ Guangzhou Road Extension Project Office, 510030 Guangzhou, China

\begin{abstract}
Glubam-concrete composite $(B C C)$ structure is a construction technique where glue-laminated bamboo beam is connected to an upper concrete slab using different types of connectors. The long-term behavior and creep mechanism of BCC system are very complex due to different time-dependent behavior of three components. This paper performed a series long-term push-out tests on four types of connections under static load. The tests lasted for a period of seven months in uncontrolled sheltered indoor condition. Important results such as the relative slip-time curves are presented in order to characterize time-dependent behavior of connectors. Furthermore creep coefficient constitutive models are provided for predicting the long-term behavior of connections.
\end{abstract}

\section{Introduction}

Glubam, a new type of glue-laminated bamboo, was developed by Xiao et al. [1]. Through designing with special laminate structure of bamboo fibers, glubam exhibits relatively higher mechanical properties compared with typical engineered lumber product, glulam (Fig.1) [2, 3]. However, for glubam-only flexural members, the main drawback of mechanical properties is of relatively low stiffness which may lead to increased deflection compared with reinforced concrete structure or steel structure. Improving the bending performance of

\footnotetext{
*Corresponding author: supershanb@hnu.edu.cn
}

glubam flexural members is a key issue for the modern bamboo structures. The glubam-concrete composite (BCC) structure is a construction technique where an upper concrete slab is connected to a lower glubam beam by shear connectors (Fig.2), allowing the best properties of both materials to be exploited, combining the high compression resistance of concrete with the greater capacity of glubam to withstand bending and tension. The mechanical performance of two materials can be utilized. Several experiments on BCC connections and beams have been performed to date [1-7]. However, the existing studies on the BCC system were focused on the short time performance. According to Code for Design of Timber Structures (GB 50005-2015), flexural members 
Table 1 Basic material properties of glubam sheet

\begin{tabular}{ccccc}
\hline Density $\left(\mathrm{kg} / \mathrm{m}^{3)}\right.$ & Elastic modulus $(\mathrm{MPa})$ & $\begin{array}{c}\text { In-plane longitudinal } \\
\text { tensile strength }(\mathrm{MPa})\end{array}$ & $\begin{array}{c}\text { Bending strength } \\
(\mathrm{MPa})\end{array}$ & $\begin{array}{c}\text { In-plane longitudinal } \\
\text { compressive strength } \\
(\mathrm{MPa})\end{array}$ \\
\hline 880 & 9407 & 82 & 99 & 51 \\
\hline
\end{tabular}

must be checked for ultimate (ULS) and serviceability limit states (SLS) at the same time. The former requires all components to meet the requirements of strength and stiffness, while the latter is mainly controlled by the maximum deflection of the structure. Some long-term studies already confirmed that the long-term deflection of timber-concrete composite (TCC) beams is significant and difficult to accurate prediction, because different time-dependent behavior of the three components such as creep of timber, shrinkage of concrete, and relatively slip of connection under long-term load [8-11].

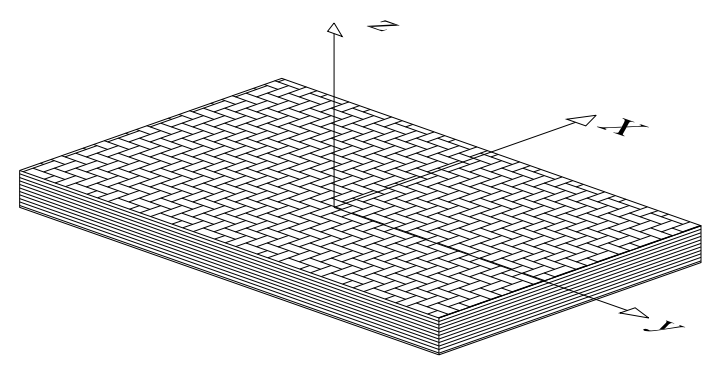

Fig. 1. Glubam sheet

Considering the differences between glubam and timber, it is necessary to investigate the long-term behavior of BCC system. Based on the short-term push-out test results of BCC system [4] , authors selected 4 types of connectors with better composite action: a continuous steel mesh connector (SM), screw connector ( $\mathrm{SC}$ ), notched connector ( NC), pre-tightening notched connector (PNC). This paper reports the results of an experimental program on testing these four types of connection systems.

The long-term tests lasted from the March 2017 till September 2017 in uncontrolled sheltered indoor condition. The most crucial quantities were recorded, including relative slips of connector, relative humidity and temperature of environment. Important results are presented herein, including connection creep coefficient and creep coefficient constitutive model. The paper provided basic data for evaluating and predicting the long-term performance of $\mathrm{BCC}$ connections.

\section{Experimental program}

\subsection{Materials and test specimens}

Glubam beam was made of four-layer glubam sheets with $28 \mathrm{~mm}$ thick. The main mechanical properties of glubam shown in Table 1 [4,7]. All connectors were glued in glubam beams by a two-component epoxy adhesive. Ordinary concrete was used, and the average cubic compressive strength was $35.0 \mathrm{MPa}$ during the testing period. Constructional reinforcement was placed in concrete slab, as HRB335 $6090 \mathrm{~mm} \times 90 \mathrm{~mm}$.

Based on the short-term performance study on connectors [4], the following four connectors were selected for long-term push-out test, as follows:

(1) A continuous steel mesh shear connector (SM) with $2 \mathrm{~mm}$ thick $\times 400 \mathrm{~mm}$ length, was made with Q235 steel plate and was actually cut from a punching-hole mesh. The steel mesh was $100 \mathrm{~mm}$ wide of which one half is glued into a slot in glubam while the other half is embedded into concrete, as shown in Fig. 2 a .

(2) The notched connector (NC) with $100 \mathrm{~mm}$ length and $50 \mathrm{~mm}$ depth, was used by combining with a screw in the glubam beam. The screw is same as SC connector that was glued in glubam beam but reached $50 \mathrm{~mm}$ into concrete, as shown in Fig. $2 b$.

(3) The screw connector (SC) utilized screws with 18 $\mathrm{mm}$ diameter. The screw was $180 \mathrm{~mm}$ length and inserted $100 \mathrm{~mm}$ deep into glubam and $80 \mathrm{~mm}$ deep into the concrete. And a nut was welded to the top to increase anchorage capacity, as shown in Fig. 2c.

(4) The pre-tightening notched connector (PNC), was consist of a notch and a dowel that dimension and specification were same as NC. It is the only prestressed connection system, in which the concrete slab is connected to glubam section by tightening the connector nut while other connection systems belong to glued 
connection types. The nut was tightened by a torque wrench 28 days after curing concrete, as shown in Fig. $2 \mathrm{~d}$.

All push-out specimens were composed of two 100 $\mathrm{mm} \times 400 \mathrm{~mm} \times 400 \mathrm{~mm}$ concrete slab and a $112 \mathrm{~mm} \times 140$ $\mathrm{mm} \times 400 \mathrm{~mm}$ glubam beam, as shown in Fig.2. The mechanical properties of the above four shear connectors were obtained by short-term push-out test, as shown in Table 2.
Table 2 Mechanical properties of one-side shear connectors

\begin{tabular}{ccccc}
\hline \multirow{2}{*}{ Specimens } & \multicolumn{3}{c}{ Slip modulus $(\mathrm{KN} / \mathrm{mm})$} & Shear strength \\
\cline { 2 - 4 } & $K_{0.4}$ & $K_{0.6}$ & $K_{0.8}$ & $F_{u}(\mathrm{KN})$ \\
\hline SM & 81.4 & 73.2 & 64.7 & 107.2 \\
BN & 53.8 & 35.3 & 6.6 & 64.5 \\
NC & 119.1 & 110 & 106.2 & 172.4 \\
PNC & 75.3 & 70.3 & 67.8 & 66.2 \\
\hline
\end{tabular}

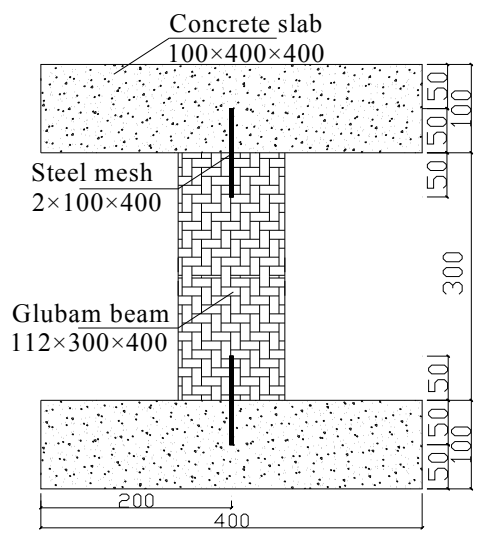

(a)

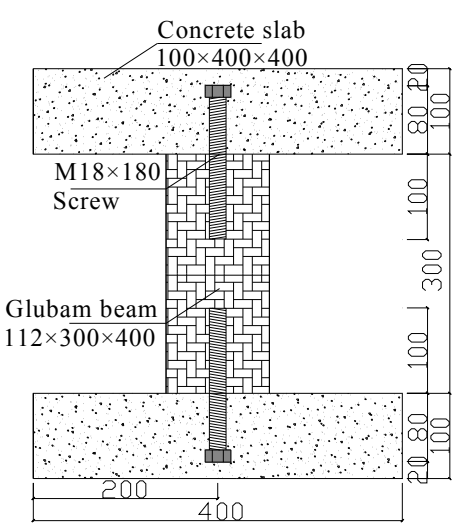

(c)

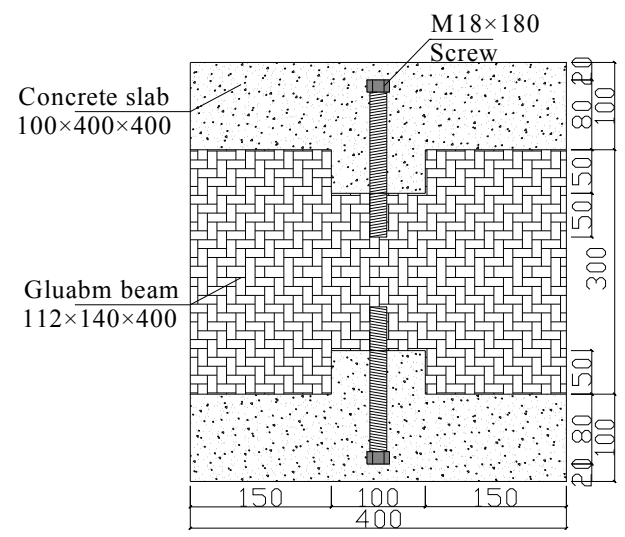

(b)

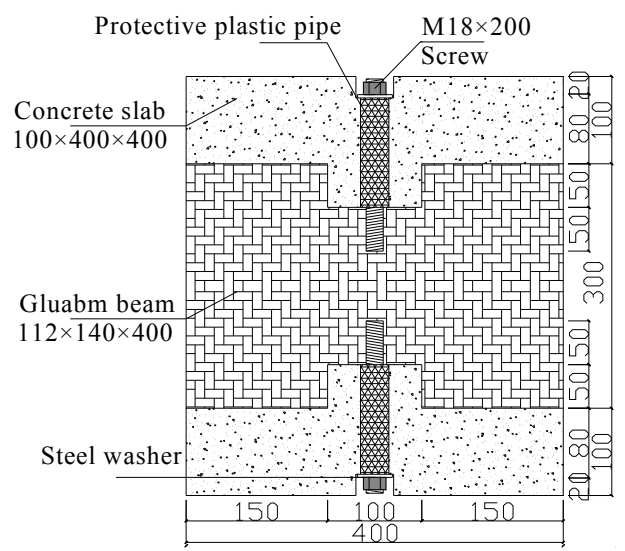

(d)

Fig. 2. Details of composite connections (unit: mm): (a) SM type; (b)NC type; (c) SC type; (d) PNC type
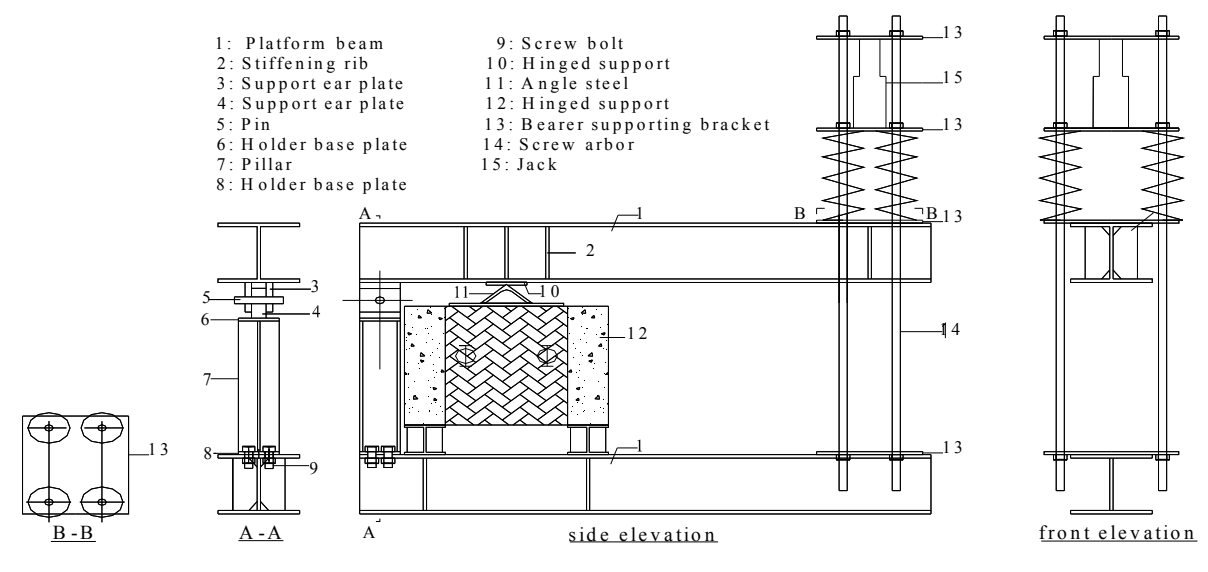

Fig. 3. The schematic illustration of long-term push-out test setup 


\subsection{Test setup}

According to some long-term push-out tests on TCC system, every shear specimens was subjected to a sustained load of approximately $0.3 F_{\mathrm{u}}$, which represents the quasi-permanent part of the serviceability design load [11], where $F_{\mathrm{u}}$ is the average ultimate load determined with the short-term shear tests on symmetrical specimen. It should be noted that the total load applied on the specimens is equal to $0.6 F_{\mathrm{u}}$ considering two connectors in each specimen.

In order to conduct the long-term test in limited room, authors has developed a new long-term test setup, as shown in Fig. 3. and Fig. 4. The experimental device utilizes leverage principle (Fig.5): $F_{1} \times L_{1}=F_{2} \times L_{2}$, $L_{1}=0.31 \mathrm{~m}, L_{2}=1 \mathrm{~m}, F_{2}=0.31 F_{1}$. The load $F_{2}$ obtains by compressing the spring with a jack. After that, the fixing nut is tightened to keep the load constant. The details of long-term sustained load are shown in Table 3.

Table 3. The details of long-term sustained load (KN)

\begin{tabular}{cccc}
\hline Specimen & $F_{u}$ & $F_{1}\left(0.6 F_{u}\right)$ & $F_{2}$ \\
\hline SM & 107.2 & 64.32 & 20 \\
SC & 64.5 & 38.7 & 12 \\
NC & 172.4 & 103.44 & 32 \\
PNC & 66.2 & 39.72 & 12.5 \\
\hline
\end{tabular}

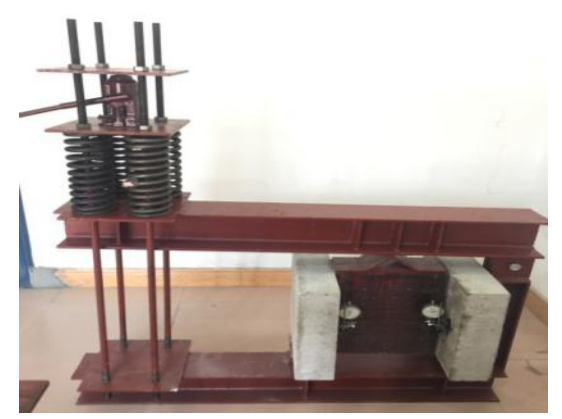

Fig. 4. Set-up of specimen in lever frame

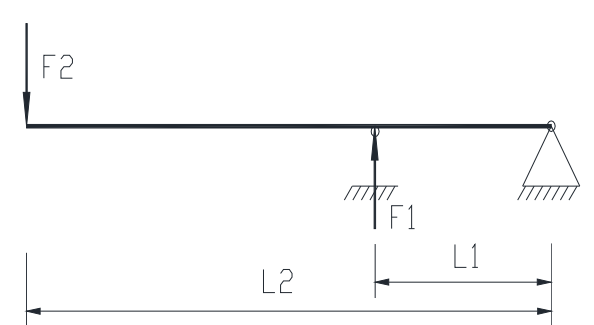

Fig. 5. leverage principle used to provide the sustained load
In the interface between glubam beam and concrete slab, 4 mechanical displacement gauges were installed to measure the relative slip. At almost same time every day, the relatively slip, as well as temperature and relative humidity of room, were record.

\section{Experimental results}

Through the analysis of experiment data for 210 days, the average relative slip-time curves of the four connectors shown in Fig.6 were obtained. It can be seen from the relative slip-time curve:

(1) All specimens exhibit initial slip $\Delta_{e l}$ at the moment of loading, and the quantity of slip is relate to the slip stiffness.

(2) The relative slip increases rapidly in the beginning of 100 days, and then its increment decreases gradually and tended to be stable.

(3) All curves are not smooth caused by varying temperature and relative humidity. Generally, this fluctuation is larger in the earlier than in the later period.

The creep coefficient is used to describe the time-dependent behavior of shear connectors in $\mathrm{BCC}$ system, and it is defined as following,

$$
\Phi(t)=\frac{\Delta(t)-\Delta_{e l}}{\Delta_{e l}}
$$

where, $\Delta(t)$ denotes the relative slip of the connection at time $t, \Delta_{e l}$ denotes the initial relative slip at beginning of load application.

Considering the actual situation, most of the long-term tests will not last for service life (50 years). Therefore, some relatively accurate long term mechanical models or creep constitutive models need be established for predicting the relatively slip over a long period on account of stable experimental data [10-12]. For SC, NC and PNC connectors, Kelvin rheological model are selected to analyze the long-term slip, and it is expressed as following,

$$
\Phi\left(t_{0}, t\right)=\sum_{i} J_{i}\left\{1-\exp \left[-\left(t-t_{0}\right) / \tau_{i}\right]\right\}
$$

where, $t_{0}$ and $t$, signify the loading time and the final time, respectively. The $J_{i}$ and $\tau_{i}$ is a constant coefficient related to material properties.

On the other hand, the slip curve of SM specimen is different from other connectors that relatively slip 


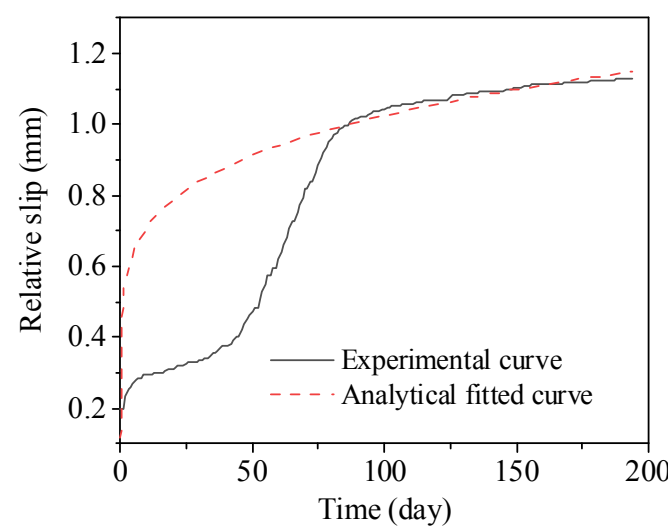

(a) SM

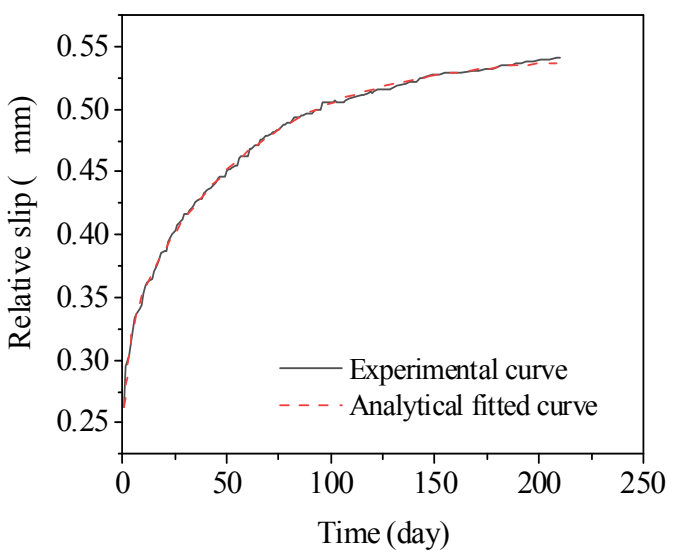

(c) NC

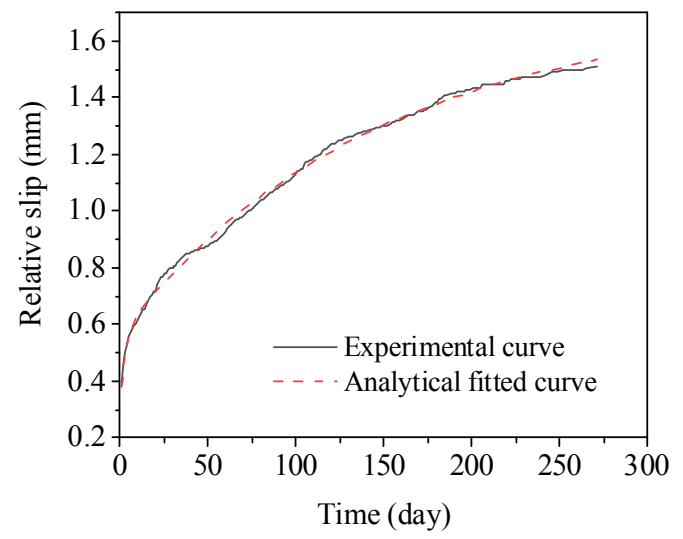

(b) SC

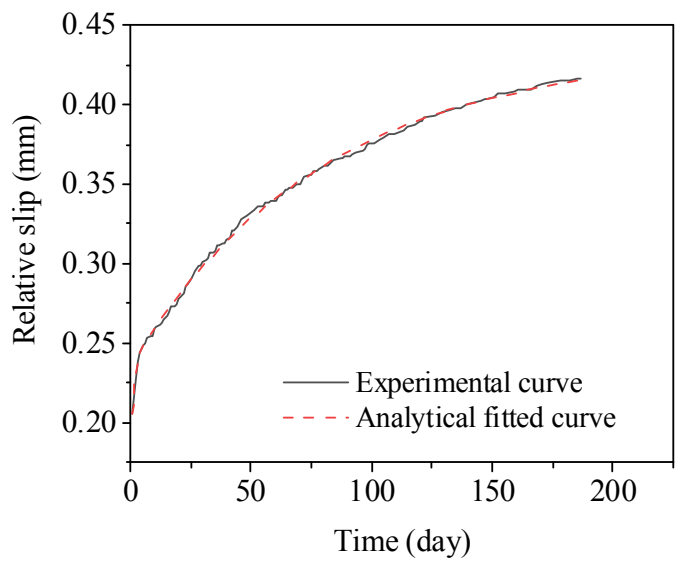

(d) PNC

Fig. 6 Trend in time of the experimental and analytical relative slip during the creep test

Table 4. Four types of creep coefficient constitutive models

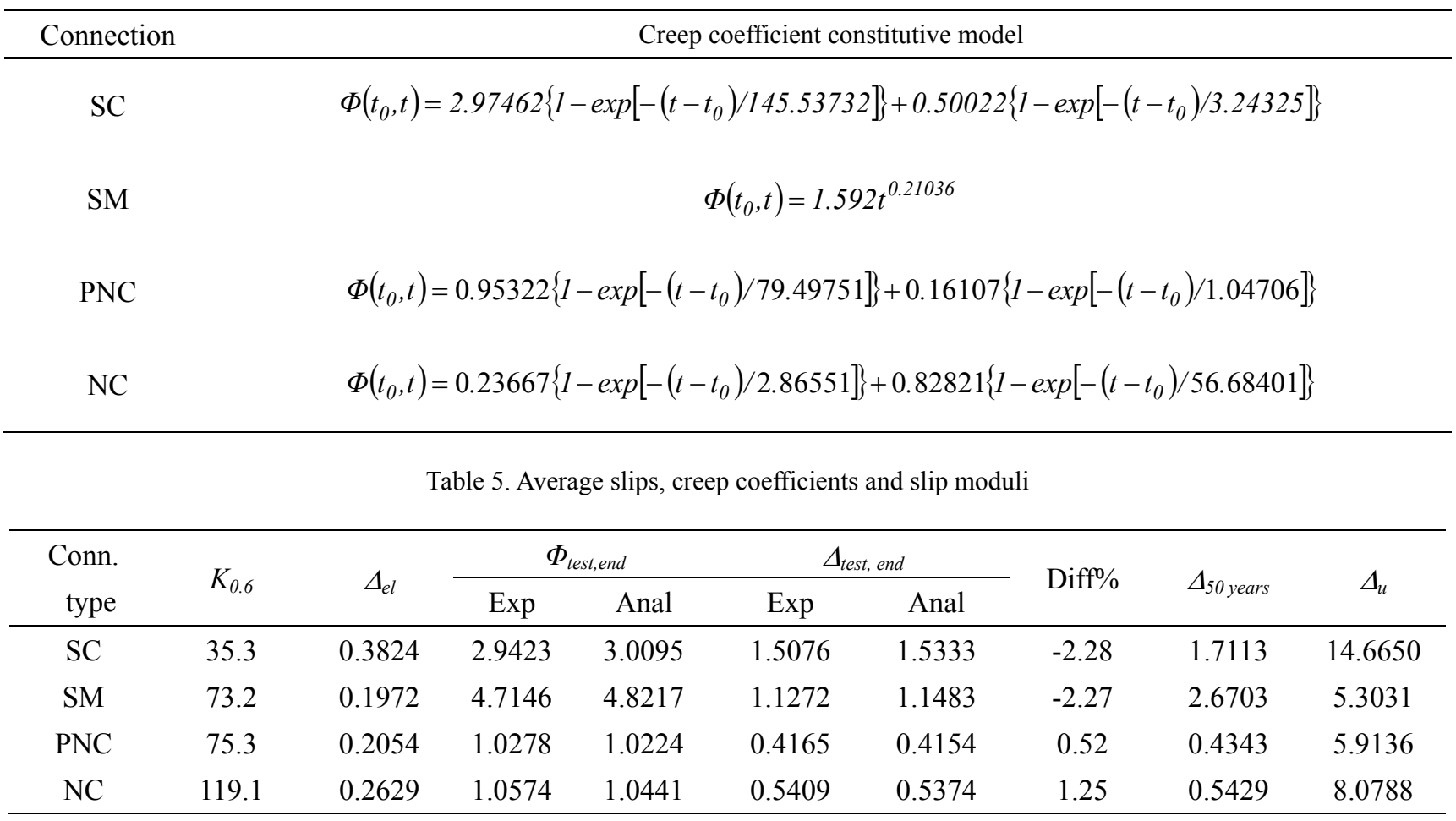

Note: $\Delta_{\text {test, end }}$ is average slip after 7 months; $\Delta_{u}$ is ultimate slip obtained from the push-out test; $\Delta_{50 \text { years }}$ is the predicting slip. 
that relatively slip increases abruptly from about $50^{\text {th }}$ day to $100^{\text {th }}$ day. So a power function model is used, as following,

$$
\Phi\left(t_{0}, t\right)=A t^{m}
$$

where, $A$ and $m$, are regression parameters coefficients.

The fitting formulas and calculating curves are shown in Table 4 and Fig. 6. Table 5 summarizes the slip modulus, initial elastic slip, the average slip, and fitting error for the tested connections. There are the large difference between the analytical fitted curve and experimental curve of specimen SM before 100 days, after that a good correspondence can be discovered. Since creep constitutive models are used to predict the long-term slip of connectors at end of service life (50 years), all tested results show that the fitting errors after 100 days is less than $3 \%$, indicating that these creep models can be used to evaluate the long-term performance of connectors. Therefore, the final slip of each connector is predicted at end of service life (50 years) and the results are also presented in Table 5. It can be observed that the predicting value under the long-term load of $0.3 F_{\max }$ is significantly lower than its ultimate slip obtained from the short-term push-out test.

\section{Conclusions}

This paper investigated the long-term slip on four types of connectors for glubam-concrete composite beam. Based on the results, the following conclusions were drawn:

(1) The relatively slip of the four types of connector increases rapidly in early stage are large, and then the increment decreases gradually and becomes stable at end of test.

(2) Kelvin rheological model and power function model are used to analyze the long-term slip of these four connectors. Compared with the test data, the proposed models are found to accurately predict the slip development within the test period.

(3) The predicting values at end of service life are significantly lower than the corresponding ultimate slips obtained from the push-out test under the long-term load of $0.3 F_{\max }$.

\section{ACKNOWLEDGEMENTS}

The experimental work of this research was conducted at the Center for Integrated Protection Research of Engineering Structures, the MOE Key Laboratory of Building Safety and Efficiency at Hunan University under the supports of the National Key R\&D Program of China (2017YFC0703502).

\section{References}

1. Y. Xiao, R.Z. Yang, B, Shan, Construct Build Mater ,44, 765 (2013)

2. B. Shan, J. Chen, Y. Xiao, Key Engineer Materials, $\mathbf{5 1 7 , 4 3}$ (2012)

3. J. Chen, Master's thesis, Hunan University (2012)

4. W.L. Zhang, Master's thesis, Hunan University (2013)

5. B. Shan, Y. Xiao, L.H. Liang, Industrial Building, 04, 9 (2015)

6. B. Shan, Z.Y. Wang, Y. Xiao, J Hunan Univ Nat Sci, 45, 97 (2018)

7. B. Shan, Y. Xiao, W.L. Zhang, B. Liu, Constr. Build. Mater, 143, 158 (2017)

8. U. Kuhlmann, B. Michelfelder, WCTE, 1 (2004)

9. B. Saïd E, JF. Jullien, A. Ceccoti, WCTE, 2 (2004)

10. A. Dias, Ph.D. Thesis, University of Coimbra, Portugal (2005)

11. D. Yeoh, Ph.D. Thesis, University of Canterbury, New Zealand (2010)

12. M. Fragiacomo, C. Amadio, L. Macorini, Mater. Struct, 40, 1013 (2007) 